\title{
The Dynamic Interfacial Oxygen Potential Between Iron-Carbon Droplets and Oxidizing Slag
}

\begin{abstract}
KEZHUAN GU, NESLIHAN DOGAN, and KENNETH S. COLEY
The dynamic nature of the interfacial oxygen potential during dephosphorization was investigated based on the concept that $P_{\mathrm{O}_{2}}$ at the interface between slag and liquid metal is determined by the balance between oxygen supply from reducible oxides in the slag and oxygen consumption by alloying elements in the metal. Combining this approach with the knowledge that at the phosphorus reversion point the interfacial oxygen potential can be determined from the bulk phosphorus partition ratio, the mass transfer coefficient for $\mathrm{FeO}, k_{\mathrm{FeO}}$, was determined for different slags and found to increase with increasing $\mathrm{FeO}$ content. In foamy slags, $k_{\mathrm{FeO}}$ was found to be a linear function of slag liquid fraction. Equating the mass transfer rate of $\mathrm{FeO}$ in the slag with decarburization rate, the dynamic interfacial oxygen potential was calculated over the course of the reaction, and its effect on the rate determining step for dephosphorization was evaluated.
\end{abstract}

DOI: $10.1007 / \mathrm{s} 11663-017-1000-2$

(C) The Minerals, Metals \& Materials Society and ASM International 2017

\section{INTRODUCTION}

IT is well known that the oxygen potential at the interface between " $\mathrm{Fe}_{\mathrm{t}} \mathrm{O}$ " containing slag and liquid iron is an important process parameter, which affects the driving force for refining reactions such as desulphurization and dephosphorization. However, since direct measurement of interfacial oxygen potential is not feasible, there is often no way to define this important parameter quantitatively. Several workers have addressed the problem of interfacial oxygen potential employing kinetic data. ${ }^{[1-4]}$ Ohguchi et al. ${ }^{[1]}$ employed a coupled reaction model to study simultaneous dephosphorization and desulphurization between molten pig iron and slag containing $\mathrm{Fe}_{2} \mathrm{O}_{3}$. They found that the interfacial oxygen activity increased firstly as the silicon transfer rate decreased, and then decreased again with the progress of the reactions. Wei et al. ${ }^{[2]}$ who investigated reactions between iron oxide bearing slag and molten iron with high carbon, proposed that the interfacial oxygen potential is defined by the balance of the rate of oxygen supply by $\mathrm{FeO}$ in the slag and consumption by carbon in the metal. They further estimated $P_{\mathrm{O}_{2}}^{i}$ based on the assumption that equilibrium

KEZHUAN GU, NESLIHAN DOGAN, and KENNETH S. COLEY are with the McMaster Steel Research Centre, Department of Materials Science and Engineering, McMaster University, 1280 Main Street West, Hamilton, ON, Canada, L8S 4L7. Contact e-mail: guk3@mcmaster.ca.

Manuscript submitted December 31, 2016.

Article published online May 31, 2017. with respect to phosphorus was established in the slag-metal system at the phosphorus reversion point, and used this to show that $P_{\mathrm{O}_{2}}^{i}$ increased with the ratio of ferric iron to total iron in the bulk slag and with the partial pressure of oxygen in the atmosphere. Using a similar approach, Monaghan et al. ${ }^{[3]}$ found that the interfacial oxygen potential was controlled primarily by $\mathrm{Fe}-\mathrm{FeO}$ equilibrium but did not find a significant dependency on the $\mathrm{Fe}^{3+} / \mathrm{Fe}^{2+}$ ratio in the slag. Based on the study of simultaneous reactions between iron-carbon alloys and slags containing different content of $\mathrm{FeO}$ and $\mathrm{MnO}$, Shibata et al. ${ }^{[4]}$ calculated that the interfacial oxygen activity for slags with high $\mathrm{FeO}$ content was approximately one order of magnitude higher than those with an equivalent content of $\mathrm{MnO}$.

Recent work by the authors ${ }^{[5]}$ highlighted that for $\mathrm{Fe}-\mathrm{C}$ droplets reacting with slag, the rate determining step and rate of dephosphorization can be changed dramatically by changes in interfacial oxygen potential during reaction. This work also showed that the phosphorus partition ratio at the reversion point decreased with increasing carbon oxidation rate. ${ }^{[2,4,5]}$ This latter result is qualitatively consistent with the findings of Wei et al. and to some extent with Shibata et al. and Monaghan et al. Given the importance of interfacial oxygen potential to refining, the current work seeks to offer a more detailed analysis of the authors' findings from dephosphorization of iron-carbon droplets and to offer comparison with previous studies under a range of reaction conditions. Experimental data from the authors' previous work are summarized in Section III and analyzed using the concept employed by Wei et al. ${ }^{[2]}$ to provide a detailed analysis of the dynamic 


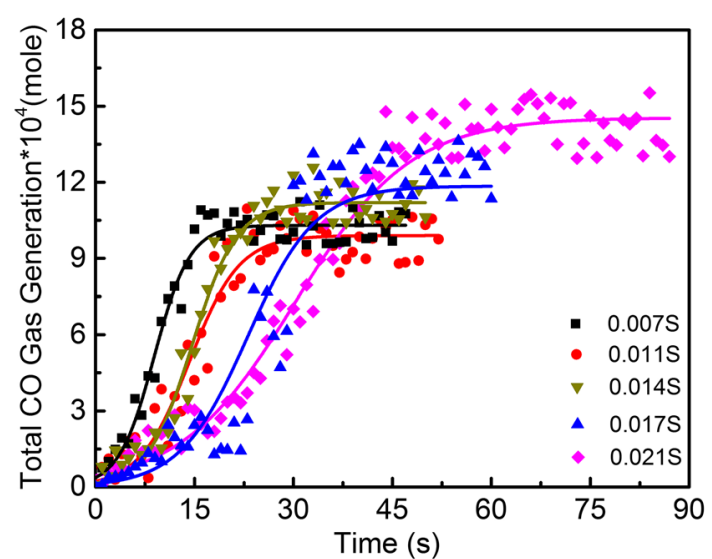

Fig. 1- $\mathrm{CO}$ gas generation with time for droplets containing different sulfur content.

interfacial oxygen potential and of oxygen $(\mathrm{FeO})$ transport in foamy slags. The results of this analysis are compared with similar analysis of the data of previous workers under a range of reaction conditions, and finally a method to calculate the interfacial oxygen potential is used to elucidate its effect on dephosphorization kinetics.

\section{EXPERIMENTAL PROCEDURE}

The primary experimental data presented in the current study are taken from a recent publication by the authors. ${ }^{[5]}$ For the convenience of the reader, a brief description of the experimental procedure is repeated here. A resistance-heated vertical tube furnace with an 80 -mm-diameter alumina working tube was used. The furnace was equipped with X-ray imaging to observe the swelling of droplets in situ and a pressure transducer to measure gas evolution using the constant volume pressure increase technique (CVPI). Experiments were done at $1853 \mathrm{~K} \quad\left(1580{ }^{\circ} \mathrm{C}\right) .25 \mathrm{~g}$ of slag, $32 \mathrm{wt}$ petCaO-35 wt petSiO ${ }_{2}-17$ wt petAl ${ }_{2} \mathrm{O}_{3}-16$ wt petFeO, was placed in a 45-mm-diameter alumina crucible located in the hot zone of the furnace, and was melted under an argon atmosphere. The Fe-C-P-S droplet, $2.62 \mathrm{wt}$ pctC-0.088 wt petP-(0.007 pet to $0.021 \mathrm{wt}$ pct)S, was dropped into the molten slag via a small hole at the bottom of a closed end alumina tube, thus ensuring the droplet was molten before entering the slag. Samples were quenched at different reaction times and taken for chemical analysis of phosphorous in the metal droplet using Inductively Coupled Plasma.

\section{RESULTS}

\section{A. Decarburization and Dephosphorization of Bloated Droplets}

Decarburization and dephosphorization data from our previous work ${ }^{[5]}$ for the reaction at $1853 \mathrm{~K}$ $\left(1580{ }^{\circ} \mathrm{C}\right)$ between slag and iron droplets with sulfur

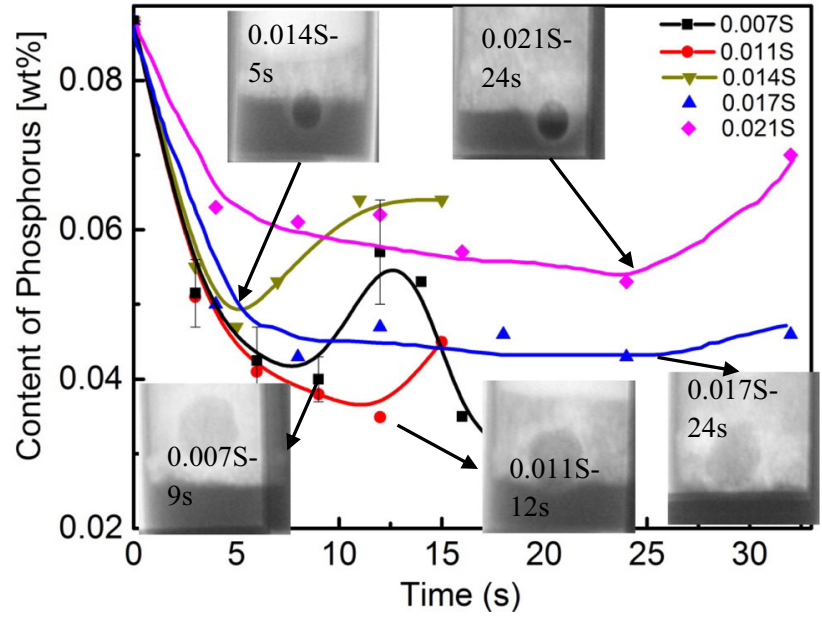

Fig. 2- Change of [pct P] with time for droplets containing different sulfur content.

contents from 0.007 and $0.021 \mathrm{wt}$ pet are summarized in Figures 1 and 2.

From Figure 1, it is possible to know the decarburization rate at any given time which can be used in analysis of the dynamic interfacial oxygen potential. During decarburization, carbon monoxide caused droplets to swell (bloating behavior) and also caused slag foaming, resulting in a layer of foamy slag sitting on top of a thinner layer of dense slag. The greater buoyancy of the bloated droplets caused them to float into the foamy slag and then, as bloating subsided, to sink back into the dense slag. In Figure 2, all droplets exhibited some reversion due to $\mathrm{FeO}$ depletion and a decrease in the rate of oxygen supply. In the case of the $0.007 \mathrm{wt}$ pctS droplet, a re-initiation of dephosphorization subsequent to reversion was observed. This can be explained if one considers that reversion occurred in the foamy slag, which was readily depleted of $\mathrm{FeO}$ because of its low liquid volume. The droplet then returned to the dense slag where there was a higher concentration of $\mathrm{FeO}$ and the dephosphorization commenced again. The decarburization and dephosphorization behavior has been discussed in detail in our previous work. ${ }^{[5]}$ In the current work, the phosphorus partition ratio at the reversion point will be used, in conjunction with the decarburization data, to evaluate the dynamic interfacial oxygen potential. Images of droplets in the slag at the point of reversion are also shown in Figure 2 for various sulfur contents. This figure shows that for droplets with 0.007 , 0.011 , and 0.017 wt pctS, the reversion occurred when metal droplets entered the foamy slag, while for droplets with 0.014 wt pctS, the reversion took place when the droplet was in transition between the dense and foamy slag. Figure 2 also shows that droplets with $0.021 \mathrm{wt}$ pctS experienced reversion when sitting between dense slag and foamy slag.

Figure 3 shows that once the droplet falls into the slag, a gas halo is formed around it and slag starts to foam at the top of dense slag. After few seconds of incubation time, the droplet swells and floats up to the foaming slag due to $\mathrm{CO}$ nucleation inside the metal 
(a) $0.007 \mathrm{~S}$
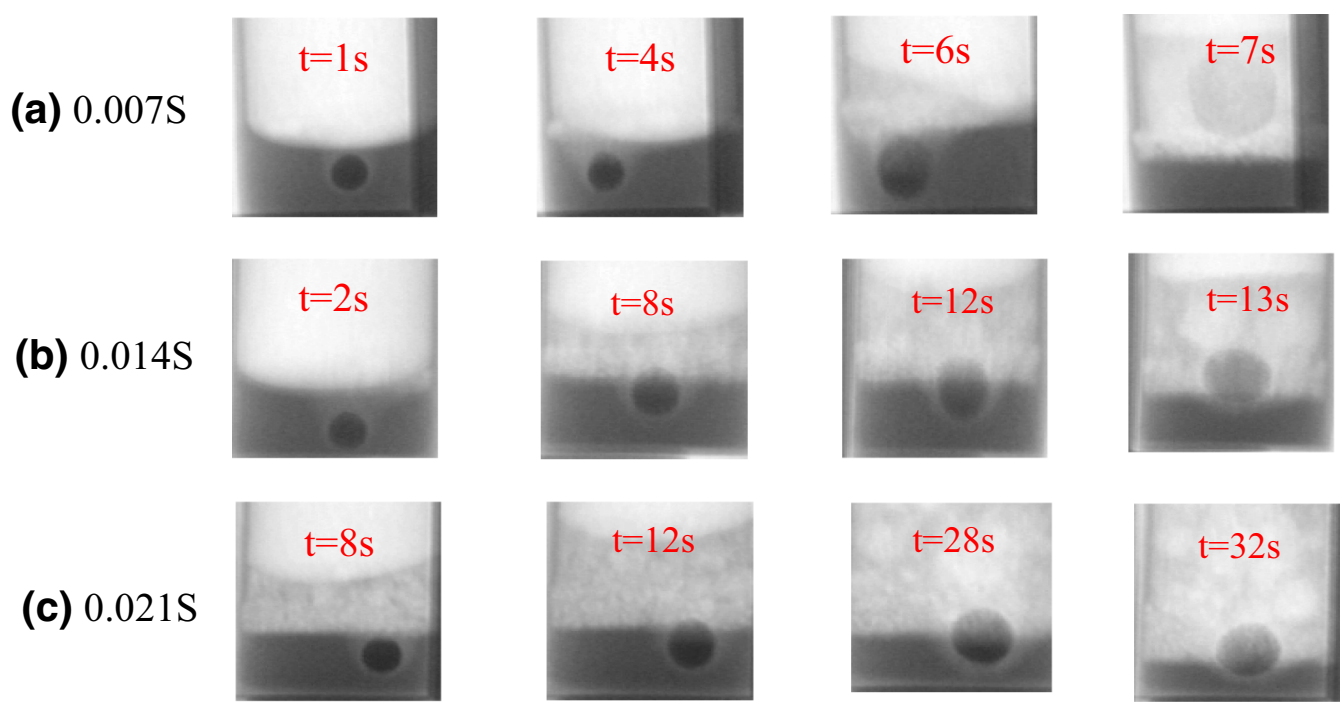

Fig. 3-Behavior of droplets before fully entering the foamy slag: $(a) 0.007 \mathrm{~S},(b) 0.014 \mathrm{~S}$ and $(c) 0.021 \mathrm{~S}$.

Table I. Calculated Results for Different Metal Droplets

\begin{tabular}{lccccc}
\hline Sulfur Content $(\mathrm{Wt} \mathrm{Pct})$ & $L_{\mathrm{P}} \times 10^{2}$ & $P_{\mathrm{O}_{2}}^{i}(\mathrm{~atm})$ & $k_{\mathrm{FeO}} \times 10^{3}(\mathrm{~cm} / \mathrm{s})$ & Liquid Slag Fraction & Void Fraction \\
\hline 0.007 & 4.8 & $5.52 \mathrm{E}-12$ & 1.44 & $0.10 \pm 0.007$ & $0.90 \pm 0.007$ \\
0.011 & 6.1 & $6.65 \mathrm{E}-12$ & 1.85 & $0.20 \pm 0.006$ & $0.80 \pm 0.006$ \\
0.014 & 3.5 & $4.28 \mathrm{E}-12$ & 10.1 & $0.92 \pm 0.020^{*}$ & $0.85 \pm 0.008$ \\
0.017 & 4.2 & $4.95 \mathrm{E}-12$ & 2.24 & $0.12 \pm 0.006$ & $0.88 \pm 0.006$ \\
0.021 & 2.6 & $3.42 \mathrm{E}-12$ & 4.87 & $0.61 \pm 0.006^{*}$ & $0.80 \pm 0.008$ \\
\hline
\end{tabular}

*These values of liquid fraction represent a weighted average of foamy and dense slag in proportion to their contact with the droplet.

droplet. The mechanism of droplet swelling has been discussed in detail in a number of recent studies. ${ }^{[6,7]}$

Inspection of the recorded $\mathrm{X}$-ray videos revealed that droplets with 0.014 and 0.021 wt petS, were sitting between dense slag and foamy slag for a while (ranged between 6 and $18 \mathrm{~s}$ ) before completely entering the foamy slag. This is shown by the series of X-ray images in Figure 3. Combining Figures 1 and 3, it is possible to have a better understanding of the three types of phosphorus reversion behavior shown in Figure 2, i.e., reversion in foamy slag (droplets with 0.007 and $0.011 \mathrm{wt}$ pctS), droplets in transition but primarily in dense slag (0.014 wt pctS), and between dense slag and foamy slag (droplets with $0.021 \mathrm{wt}$ petS). For droplets with 0.007 wt pctS, the reversion occurred entirely in the foamy slag with a low rate of transport of FeO. However, reversion in the dense slag for droplets containing $0.014 \mathrm{wt}$ pctS was probably caused by the high rate of decarburization, causing a low interfacial oxygen potential even at higher rates of oxygen supply. Despite the low rate of decarburization, if one considers the longer period spent between foamy slag and dense slag, droplets with 0.021 wt petS exhibited a phosphorus reversion because the lower mass transfer coefficient of $\mathrm{FeO}$ in the foamy slag as shown in Table I.

\section{B. Mass Transfer Coefficient of FeO and Dynamic Interfacial Oxygen Potential}

The interfacial oxygen potential is dictated by the balance between supply rate of $\mathrm{FeO}$ to the interface and the oxygen consumption by the formation of $\mathrm{CO}$ and $\mathrm{P}_{2} \mathrm{O}_{5}$. However, as the consumption of oxygen by phosphorous is negligible compared with that by carbon, at steady state this balance can be expressed as Eq. [1]:

$$
k_{\mathrm{FeO}}\left(C_{\mathrm{FeO}}^{b}-C_{\mathrm{FeO}}^{i}\right)=\frac{1}{A} \frac{\mathrm{d} n_{\mathrm{CO}}}{\mathrm{d} t} .
$$

Here, $\frac{\mathrm{d} n_{\mathrm{CO}}}{\mathrm{d} t}$ is the $\mathrm{CO}$ generation rate $(\mathrm{mol} / \mathrm{s}), C_{\mathrm{FeO}}$ is the concentration of $\mathrm{FeO}, A$ is the surface area of the droplet, $k_{\mathrm{FeO}}$ describes oxygen transport in the slag conceptually defined as the mass transfer coefficient for $\mathrm{FeO}$, and superscripts $\mathrm{b}$ and $\mathrm{i}$ indicate bulk and interfacial values, respectively. $C_{\mathrm{FeO}}^{\mathrm{i}}$ may be expressed in terms of activity of oxygen at the interface and $C_{\mathrm{FeO}}^{\mathrm{b}}$ expressed as a function of the initial value $C_{\mathrm{FeO}}^{\mathrm{O}}$ modified by the amount reduced $\left(\mathrm{d} n_{\mathrm{FeO}}\right)$. If one makes these substitutions and further recognizes that $\mathrm{d} n_{\mathrm{FeO}}$ is equivalent to the amount of $\mathrm{CO}$ generated $\left(\mathrm{d} n_{\mathrm{CO}}\right)$, one may rearrange Eq. [1] to obtain (detailed derivation of Eq. [2] from Eq. [1] is shown in the Appendix): 
$P_{\mathrm{O}_{2}}^{i}=\left[\frac{\gamma_{\mathrm{FeO}} K_{\mathrm{Fe}}}{C_{\mathrm{s}} * a_{\mathrm{Fe}}^{i} * K_{\mathrm{O}}}\left(C_{\mathrm{FeO}}^{\mathrm{o}}-\frac{1}{V_{\mathrm{S}}} \int_{n_{\mathrm{CO}, t=0}}^{n_{\mathrm{CO}, t=t}} \mathrm{~d} n_{\mathrm{CO}}-\frac{1}{A} \frac{1}{k_{\mathrm{FeO}}} \frac{\mathrm{d} n_{\mathrm{CO}}}{\mathrm{d} t}\right)\right]^{2}$,

where $K_{\mathrm{Fe}}$ and $K_{\mathrm{O}}$ are the equilibrium constants for $\mathrm{FeO}$ dissociation and oxygen dissolution in iron, $\gamma_{\mathrm{FeO}}$ is the activity coefficient for $\mathrm{FeO}$ in the slag, $C_{\mathrm{s}}$ is the overall molar density of the slag, $C_{\mathrm{FeO}}^{\mathrm{o}}$ is molar concentration of $\mathrm{FeO}$ in the slag, and $V_{\mathrm{S}}$ is the volume of slag, which could be volume of dense slag or foamy slag depending on the movement of droplet.

According to Eq. [2], the interfacial oxygen potential can be easily calculated by knowing $k_{\mathrm{FeO}}$ in the slag. Equally if knowing the interfacial oxygen potential and the decarburization rate, the $k_{\mathrm{FeO}}$ can be determined. In the current work, the interfacial oxygen potential $P_{\mathrm{O}_{2}}^{i}$ was calculated at the point of phosphorous reversion via Eq. [3]:

$$
L_{\mathrm{P}}=\frac{(\mathrm{Pct} \mathrm{P})_{i}}{[\mathrm{Pct} \mathrm{P}]_{i}}=\frac{C_{\mathrm{PO}_{4}^{3-}} P_{\mathrm{O}_{2}}^{i 5 / 4} f_{\mathrm{P}} M_{\mathrm{P}}}{K_{\mathrm{P}} M_{\mathrm{PO}_{4}^{3-}}^{3-}},
$$

where $C_{\mathrm{PO}_{4}^{3-}}$ is the phosphate capacity of the slag, $f_{\mathrm{P}}$ is the Henrian activity coefficient for phosphorus in the metal, $M_{\mathrm{P}}$ and $M_{\mathrm{PO}_{4}^{3-}}$ are the molar mass of phosphorus and phosphate, respectively, $K_{\mathrm{P}}$ is the equilibrium constant for the dissolution of phosphorus gas in steel. $C_{\mathrm{PO}_{4}^{3-}}$ was determined based on the following correlation: ${ }^{[8]}$

$$
\log C_{\mathrm{PO}_{4}^{3-}}=17.55 \Lambda+\frac{51670}{T}-21.867,
$$

where $\Lambda$ is the theoretical optical basicity of slag.

As mentioned above, at the point of phosphorus reversion, the system is instantaneously in equilibrium with respect to phosphorus while interfacial oxygen potential continues to change via the interplay between oxygen supply and consumption represented by Eq. [2] Therefore at the reversion point the bulk concentrations of phosphorus can be used to calculate $L_{\mathrm{P}}$ and thereby determine the interfacial oxygen potential. One can then calculate $k_{\mathrm{FeO}}$ by substituting $P_{\mathrm{O}_{2}}^{i}$ into Eq. [2].

The measured phosphorus partition coefficient, the calculated interfacial oxygen potential and mass transfer coefficient of $\mathrm{FeO}$ are shown in Table I. The void fraction of foamy slag at the time where reversion occurred was calculated by comparing the heights of the dense and foamy slag with that of the initial unfoamed slag and is also shown in Table I. For droplets situated between the foamy slag and dense slag at the point of reversion ( 0.014 and $0.021 \mathrm{wt} \mathrm{pctS}$ ), an average value for the slag liquid fraction was calculated based on the fraction of the surface exposed to each type of slag.

Table I shows that although the slag composition was the same, the mass transfer coefficient of $\mathrm{FeO}$ in the slag appears to vary with sulfur content of the droplet. This observation may be understood if one recognizes that the degree to which the slag is foamed will influence the mass transfer coefficient. The mass transfer coefficient of $\mathrm{FeO}$ has been determined at the point of reversion, and at that point, the droplet may be situated in the dense slag, in the foamy slag or a combination thereof. In addition, the degree to which the slag is foamed will depend on the CO generation rate. Therefore, as the $\mathrm{CO}$ generation rate is strongly affected by sulfur, it is not surprising that different mass transfer coefficients for $\mathrm{FeO}$ were determined for experiments with different metal sulfur contents. Table I also shows that in the current work, higher mass transfer coefficients were determined for slags with higher liquid fractions.

\section{DISCUSSION}

\section{A. Mass Transfer of $\mathrm{FeO}$ in the Slag}

The $k_{\mathrm{FeO}}$ determined for each case in Table I was plotted against the liquid fraction of slag in Figure 4 (detailed calculation of the liquid fraction of the slag is shown in the Appendix). It shows that a linear relationship exists between $k_{\mathrm{FeO}}$ and the fraction of liquid slag. This result is to be expected if one considers the pathway for mass transfer to be through the liquid, the cross-sectional area of the path is dramatically reduced by the presence of bubbles. Because of that, the mass transfer coefficient of $\mathrm{FeO}$ for foamy slag $\left(1.44 \times 10^{-3} \mathrm{~cm} / \mathrm{s}\right)$ is almost one tenth of the value for dense slag $\left(10 \times 10^{-3} \mathrm{~cm} / \mathrm{s}\right)$. These values are of the same order as values reported by other workers, i.e., between $10^{-2}$ and $10^{-3} \mathrm{~cm} / \mathrm{s} \cdot{ }^{[2,4,5,9-12]}$

Shibata et al. ${ }^{[2]}$ and Wei et al. ${ }^{[4]}$ have conducted similar analysis of the dynamic interfacial oxygen potential but have employed a coupled reaction model fitting all fluxes over the duration of the reaction. In their case, the mass transfer coefficient for all elements in the slag was assumed to be equal. In order to compare the approaches, $k_{\mathrm{s}}$ values from these studies are shown in Table II along with $k_{\mathrm{FeO}}$ calculated from their data using the current approach. The experimental conditions employed in the work of Shibata et al. and Wei et al. are given in the Appendix along with the method used to calculate $k_{\mathrm{FeO}}$. Calculated slag viscosity for each

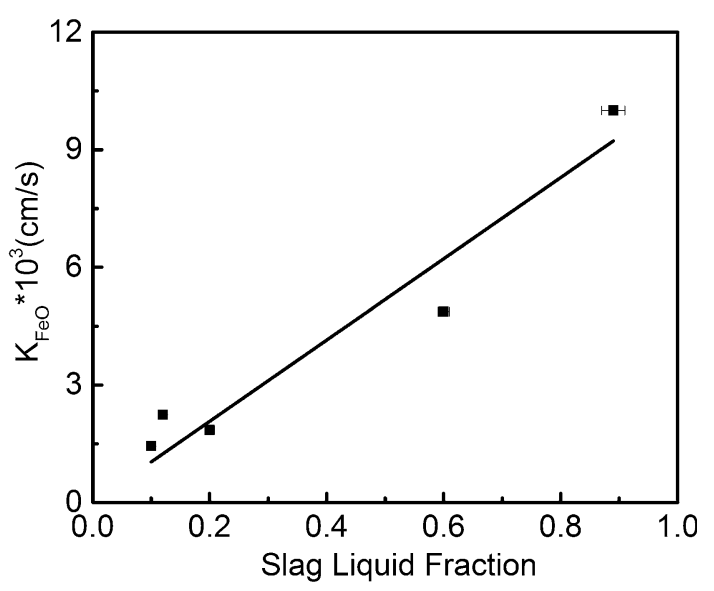

Fig. $4-k_{\mathrm{FeO}}$ as a function of the liquid fraction of slag. 
slag is also presented in Table II, determined using Factsage $6.4^{\mathrm{TM}}$ employing the Melts database.

By studying the decarburization behavior between $\mathrm{Fe}-\mathrm{C}-\mathrm{S}$ droplets and $\mathrm{CaO}-\mathrm{SiO}_{2}-\mathrm{MgO}-\mathrm{FeO}$ slags, Molloseau and Fruehan ${ }^{[9]}$ also determined $k_{\mathrm{FeO}}$ in the slag using two different methods, i.e., fitting experimental data by assuming liquid phase mass transfer was the rate controlling step, and by calculation based on penetration theory. The determined $k_{\mathrm{FeO}}$ values for slag containing 10 and $20 \mathrm{wt}$ pct $\mathrm{FeO}$ were $1.3 \times 10^{-3}$ and $3.8 \times 10^{-3} \mathrm{~cm} / \mathrm{s}$, respectively, while the values calculated from penetration model were $4.8 \times 10^{-3}$ and $1.3 \times 10^{-2} \mathrm{~cm} / \mathrm{s}$. These workers proposed that the difference obtained from these two approaches was due to the uncertainty of average diameter of $\mathrm{CO}$ bubbles formed during the reaction. The experimental $k_{\mathrm{FeO}}$ values from Molloseau and Fruehan, $1.3 \times 10^{-3}$ and $3.8 \times 10^{-3} \mathrm{~cm} / \mathrm{s}$, are used in the current work for slags containing 10 and $20 \mathrm{wt}$ pct $\mathrm{FeO}$. These have been included in Table II.

By fitting dephosphorization kinetic data, Monaghan et al. ${ }^{[3]}$ also estimated the mass transfer coefficient of phosphorous in the slag $k_{\mathrm{S}}$ for very high iron oxide slag ( $>35 \mathrm{wt}$ pct). Based on our calculations, for slag containing high iron oxide ( $>15 \mathrm{wt} \mathrm{pct})$ the determined values of $k_{\mathrm{FeO}}$ are close to a general value of $k_{\mathrm{S}}$ for all species reported by Wei et al. ${ }^{[2]}$ (15 wt pet) and Shibata et al. ${ }^{[4]}$ (29.7 wt pct) as shown in Table II. Therefore, it has been assumed for the current discussion that the values of $k_{\mathrm{s}}$ determined in the case of Monaghan et al. represent a reasonable estimate of $k_{\mathrm{FeO}}$.

For comparison of the mass transfer coefficients from other studies with those determined in the present work, it is important to know the slag void fraction. In order to estimate the void fraction of the slags in the work of Shibata et al. and Wei et al., the superficial gas velocities were calculated using decarburization data. In the case of Molloseau and Fruehan, the $\mathrm{CO}$ gas generation rate was employed to calculate the superficial gas velocities. Laboratory studies, where superficial gas velocity is lower than $10 \mathrm{~cm} / \mathrm{s}$, typically report void fractions of foaming slag between 0.8 and $0.9 .{ }^{[13,14]}$ Therefore, for the slags with total iron less than $20 \mathrm{wt}$ pct it is reasonable to assume that a void fraction is between 0.8 and 0.9 .
However, in the cases of higher total iron oxide content ( $>29.7 \mathrm{wt}$ pct), the void fraction is expected to be lower; according to Jung and Fruehan, ${ }^{[15]}$ the foaming index is dramatically decreased with the increasing of $\mathrm{FeO}$ in the slag.

Mass transfer coefficients from a range of studies have been presented in Table II. These values were determined in a number of different ways. In the current work, they have been determined specifically for $\mathrm{FeO}$ at the point of reversion of phosphorous. Molloseau and Fruehan employed a different method but also determined $k_{\mathrm{FeO}}$. In the work of Wei et al. ${ }^{[2]}$ and Shibata et al., ${ }^{[4]} k_{\mathrm{s}}$ was determined by fitting data for the transport of all species in the slag over the entire reaction time. This approach has the advantage of including a larger dataset in the calculation but may introduce errors by assuming all species have the same mass transfer coefficient. Monaghan et al. ${ }^{[3]}$ determined the mass transfer coefficient for phosphorous in the slag. The values of $k_{\mathrm{FeO}}$ presented in Table II attributed to Shibata et al. and Wei et al. were determined as part of the present work from the original data using our approach. The values for $k_{\mathrm{s}}$ were as determined by these workers. The value of $k_{\mathrm{FeO}}$ from the study of Molloseau and Fruehan ${ }^{[9]}$ was taken directly from their work. In the absence of the additional data, the value of $k_{\mathrm{s}}$ determined by Monaghan et al. is assumed to be equivalent to $k_{\mathrm{FeO}}$ which is considered reasonable because the mass transfer coefficients for different species seem to converge for high iron oxide slags. The data for mass transfer coefficients presented in Table II are plotted along with data from the current study against the $\mathrm{FeO}$ content of the slag in Figures 5(a) and (b), respectively, for low and high liquid fraction slags. The calculated viscosities in the study of Shibata et al. (29.7 wt pet $\mathrm{FeO}$ ) and the study of Monaghan et al. $(>40 \mathrm{wt}$ pct $\mathrm{FeO}$ ) are less than 0.61 poise, which is much lower compared to other cases; therefore, the liquid fraction for these slags would be expected to be much higher. Therefore, we have compared the $k_{\mathrm{FeO}}$ data for droplets with 0.014 and $0.021 \mathrm{wt}$ petS in current study, i.e., those for which the slag had a high liquid fraction with cases from Shibata et al. and Monaghan et al. containing high total iron oxide ( $>29 \mathrm{wt}$ pct) as shown in Figure 5(b).

Table II. Calculated $k_{\mathrm{FeO}}$ for Different Researchers' Work

\begin{tabular}{|c|c|c|c|c|c|c|}
\hline Investigator & $\mathrm{T}\left[\mathrm{K}\left({ }^{\circ} \mathrm{C}\right)\right]$ & $\mathrm{Fe}_{t} \mathrm{O}(\mathrm{Wt} \mathrm{Pct})$ & $\eta$ (Poise) & $V_{\mathrm{g}}^{\mathrm{s}}(\mathrm{cm} / \mathrm{s})$ & $k_{\mathrm{s}} \times 10^{3}(\mathrm{~cm} / \mathrm{s})$ & $k_{\mathrm{FeO}} \times 10^{3}(\mathrm{~cm} / \mathrm{s})$ \\
\hline Wei et al. & $1573(1300)$ & 15 & 0.86 & 0.11 & 3 & 1.37 \\
\hline Wei et al. & $1573(1300)$ & 15 & 0.86 & 0.10 & 3 & 2.09 \\
\hline Shibata et al. & $1723(1450)$ & 0 & 0.59 & 0.17 & 5 & 0.87 \\
\hline Shibata et al. & $1723(1450)$ & 5.4 & 0.41 & 0.22 & 6 & 0.88 \\
\hline Shibata et al. & $1773(1500)$ & 4.5 & 0.78 & 0.06 & 16.7 & 1.11 \\
\hline Shibata et al. & $1773(1500)$ & 29.7 & 0.61 & 0.60 & 13.3 & 15.1 \\
\hline Molloseau and Fruehan. & $1713(1440)$ & 10 & 1.51 & 0.06 & & 1.3 \\
\hline Molloseau and Fruehan. & $1713(1440)$ & 20 & 1.02 & 0.4 & & 3.8 \\
\hline Monaghan et al. & $1603(1330)$ & 38.10 & 0.80 & & 3.6 & \\
\hline Monaghan et al. & $1603(1330)$ & 47.62 & 0.58 & & 10 & \\
\hline Monaghan et al. & $1603(1330)$ & 57.14 & 0.42 & & 28 & \\
\hline Monaghan et al. & $1603(1330)$ & 66.67 & 0.30 & & 99 & \\
\hline This study & $1853(1580)$ & 16 & 1.49 & $0.30-0.40$ & & $1.0-10$ \\
\hline
\end{tabular}


By studying reduction of iron oxide in FeO-rich slag, most investigators ${ }^{[16-24]}$ proposed that the reaction was first order with respect to $\mathrm{FeO}$ concentration in the bulk slag, and was most likely controlled by $\mathrm{FeO}$ mass transfer in the slag. If this is the case, the apparent rate constant can be converted to a mass transfer coefficient for $\mathrm{FeO}$ in the slag as done by Woolley and Pal. ${ }^{[24]} \mathrm{A}$ detailed explanation of this conversion is shown in the Appendix. Depending on the availability of required information to complete the conversion, apparent rate constants in some of those studies were converted and included in Figures 5(a) and (b), also listed in the appendix in Table AIV. When carbon dissolved from a graphite crucible was the reductant for $\mathrm{FeO}$, Galgali et al $^{[17]}$ found that the mass transfer coefficient of $\mathrm{FeO}$ decreased with the increasing of $\mathrm{FeO}$ content in the slag. Although in the case of Murthy et al. ${ }^{[18]}$ the apparent rate constant showed an increase, the converted $k_{\mathrm{FeO}}$ was found to decrease slightly with increasing $\mathrm{FeO}$ content. Apparently, a further detailed analysis of these last two studies is required in order to understand this discrepancy. The $k_{\mathrm{FeO}}$ in these cases were also listed in Table AIV, but have not been brought into this discussion. It is worth noting that other workers ${ }^{[22,24]}$ have successfully correlated $k_{\mathrm{FeO}}$ with the rate of $\mathrm{CO}$ bubble generation to justify the effect of $\mathrm{FeO}$ content on $k_{\mathrm{FeO}}$.

All the data presented in Figure 5 show an excellent fit to a parabolic relationship between total iron oxide and the mass transport coefficient of $\mathrm{FeO}$ in the slag. Molloseau and Fruehan ${ }^{[7]}$ and Sarma ${ }^{[8]}$ also observed a similar effect of $\mathrm{FeO}$ in the slag on mass transfer coefficient of $\mathrm{FeO}$ but did not offer a detailed explanation. From Figure 5, it is interesting to note that comparing data for high and low liquid fraction slags, they scale in reasonable approximation to the ratio of liquid fraction. It is also worth pointing out that in Figure 5(a), although the $k_{\mathrm{FeO}}$ in the case of $\mathrm{Li}$ and Barati $^{[16]}$ follows a parabolic function, its values are lower than other cases due to the higher slag basicity ( $B=1.8)$ compared to that $(B=\sim 1)$ employed in other studies. High basicity slag would increase the effective viscosity as shown by $\mathrm{Li}$ and Barati, ${ }^{[16]}$ which leads to a higher foam index ${ }^{[15]}$ and lower liquid fraction.

In the current case, we are expressing oxygen transfer as mass transport of $\mathrm{FeO}$. However, it is more realistic to consider oxygen to be transported in the form of either $\mathrm{O}^{2-}$ or singly charged oxygen species hopping from site to site on silicate chains. Therefore, the flux will require charge balancing either by concurrent transport of cations or by countercurrent transport of electrons. Barati and Coley ${ }^{[25]}$ demonstrated that at $\mathrm{FeO}$ contents of greater than 5 pct, electronic conduction via small polaron hopping was dominant and that the electronic conductivity was a parabolic function of total iron oxide content. Therefore, if in the current case, oxygen transport is controlled by the conduction of charge balancing electrons, the nominal mass transfer coefficient of $\mathrm{FeO}, k_{\mathrm{FeO}}$ can be expected to follow a parabolic relationship with total iron in the slag. All the data in Figure 5 from different researchers under a wide ranged temperatures show an excellent fit, which suggests that the effect of temperature on the $k_{\mathrm{FeO}}$ was relatively small. This observation is not consistent with the temperature effect on electronic conductivity observed by Barati and Coley. ${ }^{[26]}$ Employing the Melts database in Factsage $6.4^{\mathrm{TM}}$, the activation energy of viscous flow for several cases in Figure 5 was estimated to have a magnitude of $100 \mathrm{~kJ} / \mathrm{mol}$. This estimation indicates that the temperature might have a larger effect on mass transfer coefficient than implied by Figure 5. At present the authors cannot offer a definitive explanation for this discrepancy.

\section{B. Dynamic Interfacial Oxygen Potential}

Knowing $k_{\mathrm{FeO}}$ in the slag, the interfacial oxygen potential between bloated metal droplets and slag can be calculated based on Eq. [2]. According to the results in Table II, mass transfer of $\mathrm{FeO}$ in dense slag is more than four times faster than in foamy slag. In the present work, dephosphorization was mostly complete before droplets entered the foamy slag. Therefore, only the $P_{\mathrm{O}_{2}}^{i}$ at the initial stage, before the metal droplet completely

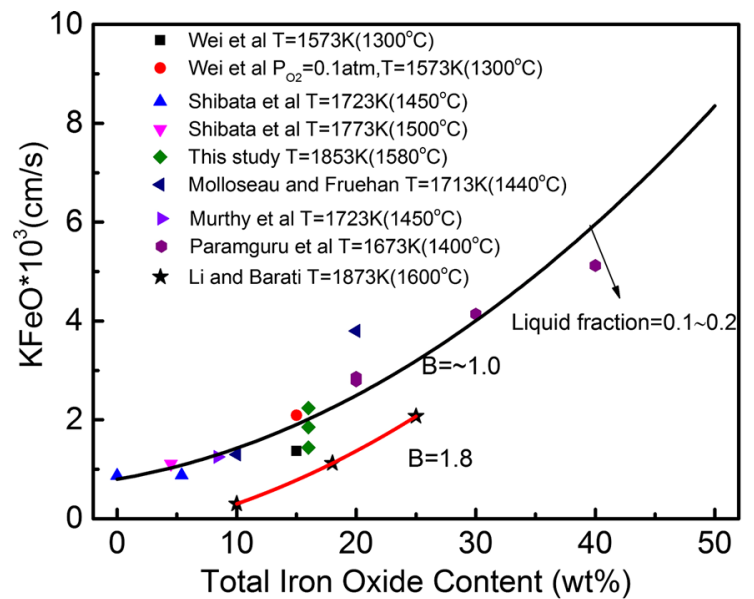

(a)

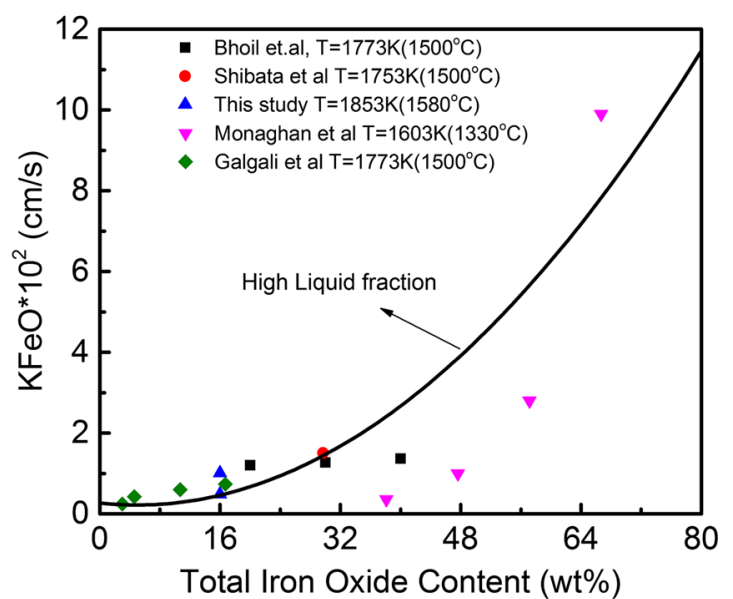

(b)

Fig. 5- $k_{\mathrm{FeO}}$ as a function of total iron content in the slag: (a) low liquid fraction and $(b)$ high liquid fraction. 


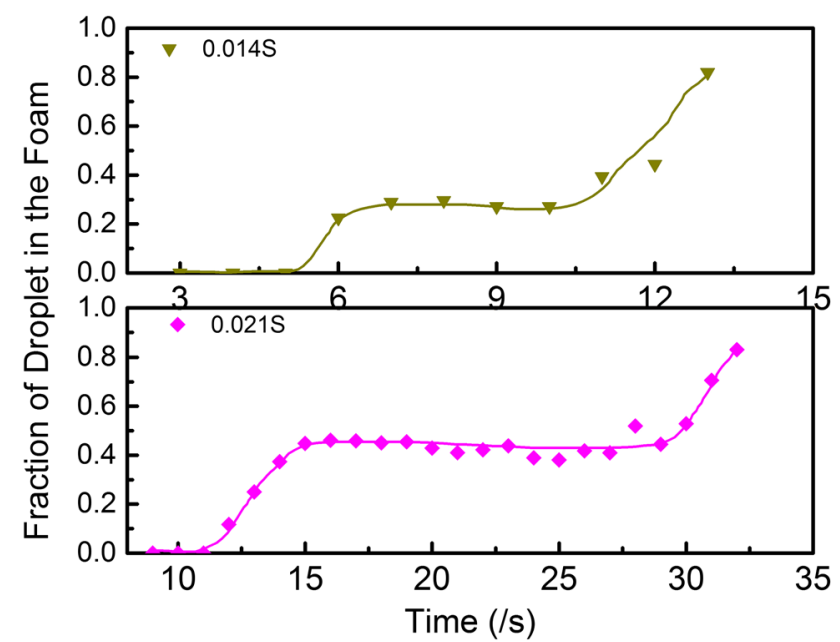

Fig. 6-Fraction of droplet surface area in the foam as a function of time.

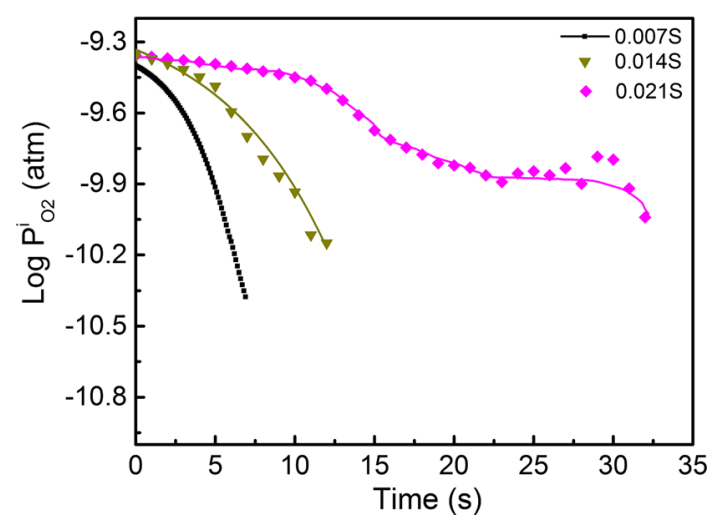

Fig. 7-The dynamic interfacial oxygen potential between bloated droplets and slag.

enters the foamy slag, was calculated. As examples of the range of droplet behavior observed in the current work, the dynamic interfacial oxygen potential was calculated for droplets with $0.007,0.014$, and $0.021 \mathrm{wt}$ petS.

To account for periods in which droplets sit between the foamy slag and dense slag, the changing fraction of droplet surface area in the foamy slag was measured and plotted in Figure 6 for droplets with 0.014 and $0.021 \mathrm{wt}$ pctS. After approximately 5 seconds, $0.014 \mathrm{wt}$ pctS droplets start to float up into the foamy slag, while $0.021 \mathrm{wt}$ petS droplets begin to float up after around 12 seconds due to their longer incubation time for swelling. The mass transfer coefficient $k_{\mathrm{FeO}}$ used to calculate the interfacial oxygen potential was calculated as an average of foamy slag and dense slag weighted according to the fraction of the droplet surface exposed to each.

Based on Eq. [2], the dynamic interfacial oxygen potential for droplets before rising entirely into the foamy slag was calculated and is shown in Figure 7.
This shows that $P_{\mathrm{O}_{2}}^{i}$ for all the cases decreases as reaction proceeds but the rate of decrease varies with the decarburization rate and incubation time. For droplets with lower sulfur content ( 0.007 and $0.014 \mathrm{wt}$ pct), the $P_{\mathrm{O}_{2}}^{i}$ drops very rapidly because their short incubation times leading to an early entry into the foamy slag which has a low mass transfer coefficient for $\mathrm{FeO}$ and also the low liquid volume becomes depleted of $\mathrm{FeO}$. While for droplets with $0.021 \mathrm{wt}$ pctS, $P_{\mathrm{O}_{2}}^{i}$ decreases much more slowly because of the lower decarburization rate coupled with the longer incubation period which causes them to remain in the dense slag with a higher mass transfer coefficient for $\mathrm{FeO}$ and greater reservoir of $\mathrm{FeO}$.

One would assume that in a real BOF, the droplets would be subject to the $k_{\mathrm{FeO}}$ of a foamy slag but that $\mathrm{FeO}$ would not be depleted because of constant replenishing via reaction with the oxygen jet.

\section{The Effect of Dynamic Interfacial Oxygen Potential on Dephosphorization Kinetics}

It is well established that the balance between control by mass transfer in the slag and by mass transfer in the metal is heavily influenced by the phosphorus partition ratio; a significant change in $L_{P}$ causes a shift in reaction mechanism from one controlling step to another. ${ }^{[2,4,5]}$ By knowing the dynamic $P_{\mathrm{O}_{2}}^{i}$, the phosphorus partition ratio $L_{\mathrm{P}}$ and the overall mass transfer coefficient $k_{\mathrm{o}}$ can be calculated as a function of time based on Eq. [3] and [5]:

$$
k_{\mathrm{o}}=\frac{1}{\frac{\rho_{\mathrm{m}}}{k_{\mathrm{s}} \rho_{\mathrm{s}} L_{\mathrm{P}}}+\frac{1}{k_{\mathrm{m}}}},
$$

where $k_{\mathrm{s}}$ and $k_{\mathrm{m}}$ are mass transfer coefficients in slag and metal phase, respectively.

Figure 8 shows the phosphorous partition ratio and the overall mass transfer coefficient as a function of time for bloated droplets in the current study, calculated based on the dynamic interfacial oxygen potential. Here, $k_{\mathrm{s}}$ and $k_{\mathrm{m}}$ were chosen to be 0.01 and $0.085 \mathrm{~cm} / \mathrm{s}$ based on analysis of dephosphorization presented in a previous publication by the authors. ${ }^{[5]}$

Figure 8(a) shows that the driving force for dephosphorization, $L_{\mathrm{P}}$, decreases with time due to the decreasing interfacial oxygen potential as reduction of $\mathrm{FeO}$ from the slag proceeds. Figure 8(b) presents the change of overall mass transfer coefficient during the dephosphorization period shown in Figure 2. It shows that the controlling step for dephosphorization of bloated droplets in the current study is initially mixed control by mass transport in both the metal and slag. And the value of $k_{0}$ is $0.03 \mathrm{~cm} / \mathrm{s}$. As phosphorus partition ratio decreases, the rate determining step shifts to mass transport in slag with a value of $k_{0}$ less than $0.01 \mathrm{~cm} /$ $\mathrm{s}$. The changes in $k_{0}$ with time agree very well with the authors' previous observations of dephosphorization kinetics. ${ }^{[5]}$

Shibata et al. ${ }^{[4]}$ conducted a similar analysis of mixed control to that presented above; however, these workers presented their data as resistance to mass transfer rather 


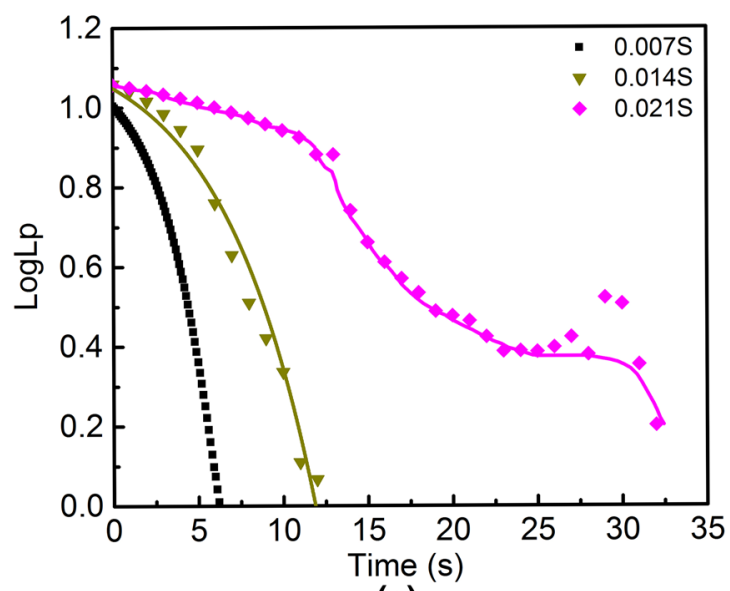

(a)

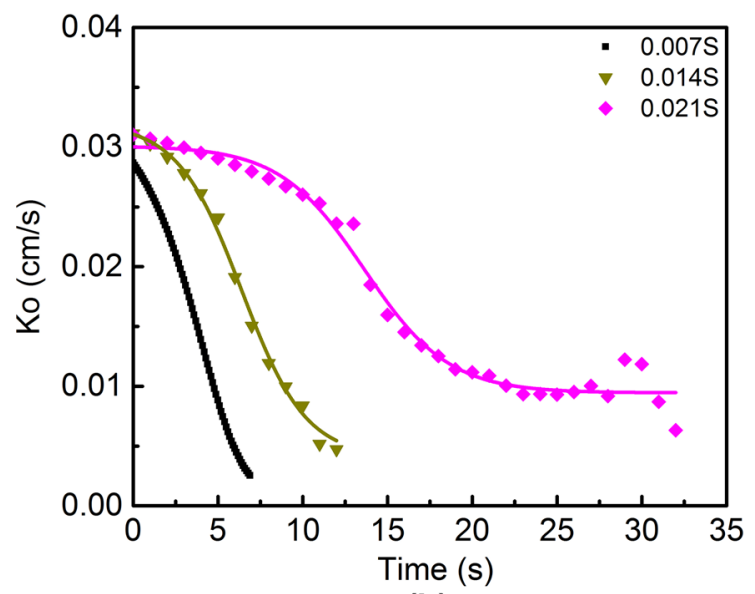

(b)

Fig. 8 - (a) Phosphorus partition ratio $\left(L_{\mathrm{P}}\right)$ and $(b)$ overall mass transfer coefficient $\left(k_{0}\right)$ as a function of time for the study of bloated droplets.

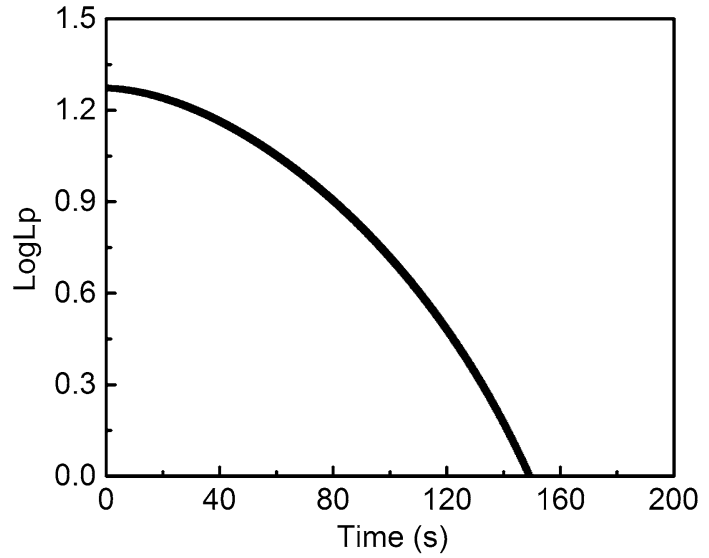

(a)

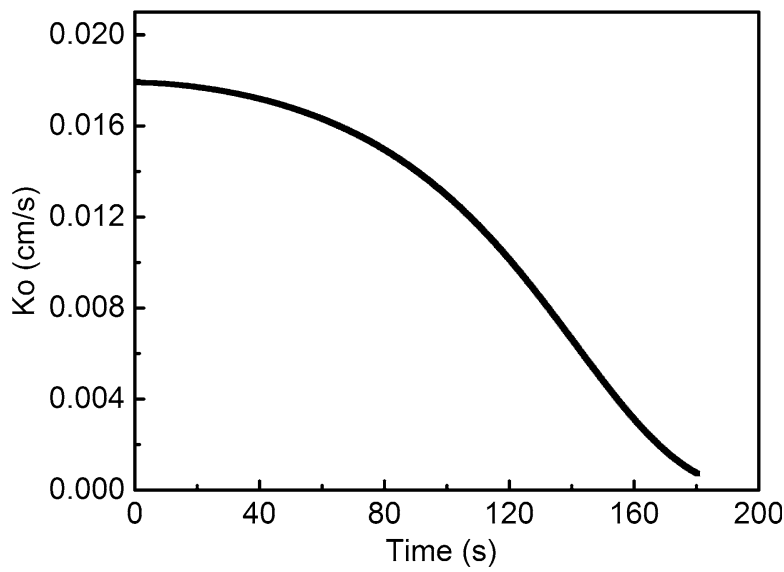

(b)

Fig. 9-(a) $L_{\mathrm{P}}$ and (b) $k_{0}$ as a function of time for the slag in Shibata's work.

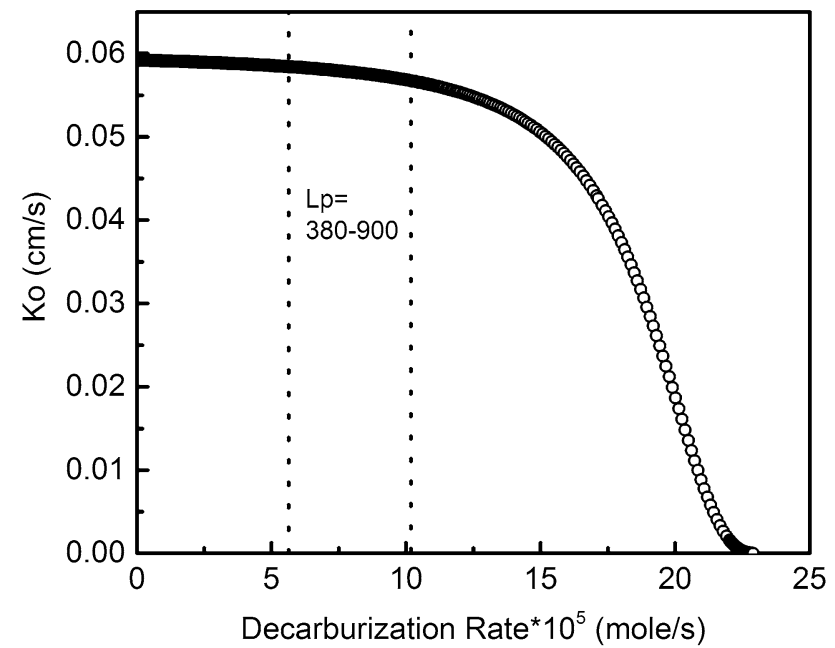

Fig. 10 - The effect of decarburization rate on overall mass transfer coefficient. than an overall mass transfer coefficient. To facilitate comparison, Shibata's data analyzed in terms of $k_{0}$ is presented in Figure 9. These workers reported $k_{\mathrm{s}}$ and $k_{\mathrm{m}}$ to be 0.013 and $0.021 \mathrm{~cm} / \mathrm{s}$. Using these values, the determined $L_{\mathrm{P}}$ and $k_{0}$ are shown in Figure 9. The trends presented in Figure 9 are exactly the same as those found in the current authors' research, although the overall mass transfer coefficient is relatively lower. Deeper analysis shows that the source of the discrepancy lies in the current case having a significantly higher mass transfer coefficient for phosphorus in the metal. The authors are not able to offer a definitive explanation for this discrepancy but believe it must be related to the way in which $\mathrm{CO}$ gas stirs the metal. It is worth noting that in the current case, $\mathrm{CO}$ nucleated throughout the droplet.

The relative contribution of the metal phase to the overall resistance to mass transport was determined by Shibata et al. to be 95 pct at the beginning of the reaction decreasing to $30 \mathrm{pct}$ towards the end of the reaction. The relatively greater fraction of control by 
mass transport in the metal when compared with the current work can be explained by less depletion of $\mathrm{FeO}$ in the slag in the case of Shibata et al. and by a lower mass transfer coefficient in the metal.

From above discussion, the rate controlling step of dephosphorization is dependent on the decarburization behavior of metal droplets. The prediction of rate determining step using the model developed in the current study showed very reasonable agreement with other researchers' work. ${ }^{[2-4]}$ Therefore, it is worth examining how the decarburization rate might affect the rate controlling step in real steelmaking conditions. Assuming metal droplets under typical steelmaking conditions have similar decarburization behavior to droplets with 0.014 wt petS in this study, and choosing reasonable mass transfer coefficients for slag $(0.005 \mathrm{~cm} /$ s) and metal $(0.06 \mathrm{~cm} / \mathrm{s})$ based on the above discussion, the relationship between overall mass transfer coefficient $k_{o}$ and the decarburization rate has been evaluated using the above model. In this calculation, the slag composition was chosen to be $45 \mathrm{wt}$ petCaO-20 wt petSiO $_{2}-15$ wt petFeO-10 wt petMnO-5 wt petMgO based on typical industrial data during the middle blow stage in the BOF. ${ }^{[27]}$ The calculated result is shown in Figure 10. The two vertical dotted lines represent the range of decarburization rate observed in this study at $1853 \mathrm{~K}\left(1580{ }^{\circ} \mathrm{C}\right)$. The corresponding $L_{\mathrm{P}}$ for a steelmaking slag will be between 380 and 900. This figure shows that under steelmaking conditions, dephosphorization of metal droplets in the emulsion zone is more likely to be limited by the mass transport in the metal phase. This finding is reasonable under steelmaking conditions if one considers the high basicity of slag and no depletion of $\mathrm{FeO}$ in the slag.

\section{CONCLUSION}

The dynamic interfacial oxygen potential between bloated droplets and slag was determined using the phosphorus partition ratio at the reversion point. Analysis of this data by considering the balance between oxygen supply from oxidizers in the slag and oxygen consumption by alloy elements in the metal allowed the mass transfer coefficient of "FeO" to be determined. The mass transfer coefficient was found to show a parabolic increase with total iron oxide in the slag. The calculated results also showed that the mass transfer of $\mathrm{FeO}$ in dense slag was much faster than in foamy slag. Knowing the mass transfer coefficient for $\mathrm{FeO}$ and the decarburization rate of the droplet allows the dynamic interfacial oxygen potential to be calculated at any time during the reaction. From this study, the following conclusions can be drawn.

1. When the mass transfer of oxygen in the slag is represented as mass transfer of "FeO," the mass transfer coefficient shows a parabolic correlation with total iron oxide in the slag and is not strongly dependent on temperature. This is consistent with transport controlled by charge balancing by small polaron hopping via an $\mathrm{Fe}^{3+} / \mathrm{Fe}^{2+}$ couple.
2. The mass transfer coefficient of FeO in the dense slag shows a strong linear correlation with the liquid fraction in foamy slag due to transport pathways being limited to the liquid portion.

3. Calculations predict that the rate determining step for dephosphorization of bloated droplets in laboratory studies, shifts from mass transport in both metal and slag to mass transport in slag. This is caused by a decrease in the dynamic interfacial oxygen potential with time because of $\mathrm{FeO}$ depletion.

4. Contrary to most laboratory studies, the calculation method adopted in the current study shows that dephosphorization of metal droplets in the emulsion zone under real steelmaking conditions will be limited by mass transport in the metal phase because of the high basicity of the slag and the fact that $\mathrm{FeO}$ is continuously replenished.

\section{ACKNOWLEDGMENTS}

The authors thank member companies of McMaster Steel Research Centre and the Natural Science and Engineering Research Council of Canada (NSERC) for funding this project.

\section{APPENDIX}

\section{Derivation of Equation [2]}

The derivation of Eq. [2] from Eq. [1] can be demonstrated as follows:

$$
k_{\mathrm{FeO}}\left(C_{\mathrm{FeO}}^{\mathrm{b}}-C_{\mathrm{FeO}}^{\mathrm{i}}\right)=\frac{1}{A} \frac{\mathrm{d} n_{\mathrm{CO}}}{\mathrm{d} t},
$$

where $C_{\mathrm{FeO}}^{\mathrm{b}}$ is the instantaneous concentration of $\mathrm{FeO}$ in the bulk slag at any given time $t$, which can be calculated via Eq. [A1] by knowing the amount of $\mathrm{FeO}$ $\left(n_{\mathrm{FeO}}\right)$ that has been reduced, i.e., the amount of $\mathrm{CO}$ gas $\left(n_{\mathrm{CO}}\right)$ generated at time $t$.

$$
C_{\mathrm{FeO}}^{\mathrm{b}}=C_{\mathrm{FeO}}^{\mathrm{o}}-\frac{1}{V_{\mathrm{S}}} n_{\mathrm{FeO}}=C_{\mathrm{FeO}}^{\mathrm{o}}-\frac{1}{V_{\mathrm{S}}} \int_{n_{\mathrm{CO}, t=0}}^{n_{\mathrm{CO}, t=t}} \mathrm{~d} n_{\mathrm{CO}} .
$$

Substituting $C_{\mathrm{FeO}}^{\mathrm{b}}$ into Eq. [1], one can obtain the concentration of $\mathrm{FeO}$ at the slag-metal interface.

$$
C_{\mathrm{FeO}}^{i}=C_{\mathrm{FeO}}^{\mathrm{o}}-\frac{1}{V_{\mathrm{S}}} \int_{n_{\mathrm{CO}, t=0}}^{n_{\mathrm{CO}, t=t}} \mathrm{~d} n_{\mathrm{CO}}-\frac{1}{A} \frac{1}{k_{\mathrm{FeO}}} \frac{\mathrm{d} n_{\mathrm{CO}}}{\mathrm{d} t} .
$$

The equilibrium constant for dissociation of $\mathrm{FeO}$ at the interface can be expressed as,

$$
K_{\mathrm{Fe}}=\frac{a_{\mathrm{Fe}}^{i} a_{\mathrm{O}}^{i}}{\gamma_{\mathrm{FeO}} X_{\mathrm{FeO}}^{i}} .
$$


Knowing the overall molar density of slag $C_{\mathrm{s}}, X_{\mathrm{FeO}}^{i}$ can be expressed as $\frac{C_{\mathrm{FeO}}^{i}}{C_{\mathrm{s}}}$. Then $a_{\mathrm{O}}^{i}$ can be written as Eq. [A4] by rearranging Eq. [A3],

$$
a_{\mathrm{O}}^{i}=\frac{\gamma_{\mathrm{FeO}} K_{\mathrm{Fe}}}{C_{\mathrm{s}} a_{\mathrm{Fe}}^{i}} C_{\mathrm{FeO}}^{i} .
$$

Substituting Eq. [A2] into Eq. [A4], one can obtain,

$a_{\mathrm{O}}^{i}=\frac{\gamma_{\mathrm{FeO}} K_{\mathrm{Fe}}}{C_{\mathrm{s}} a_{\mathrm{Fe}}^{i}}\left(C_{\mathrm{FeO}}^{\mathrm{o}}-\frac{1}{V_{\mathrm{S}}} \int_{n_{\mathrm{CO}, t=0}}^{n_{\mathrm{CO}, t=t}} \mathrm{~d} n_{\mathrm{CO}}-\frac{1}{A} \frac{1}{k_{\mathrm{FeO}}} \frac{\mathrm{d} n_{\mathrm{CO}}}{\mathrm{d} t}\right)$.

Considering the dissolution of oxygen into metal phase with the following reaction constant,

$$
K_{\mathrm{O}}=\frac{a_{\mathrm{O}}^{i}}{P_{\mathrm{O}_{2}}^{i l / 2}} \Rightarrow P_{\mathrm{O}_{2}}^{i l / 2}=\frac{a_{\mathrm{O}}^{i}}{K_{\mathrm{O}}}
$$

the expression for calculating oxygen potential (equivalent oxygen partial pressure) at the slag-metal interface can be expressed as Eq. [2] finally.

$$
P_{\mathrm{O}_{2}}^{i}=\left[\frac{\gamma_{\mathrm{FeO}} K_{\mathrm{Fe}}}{C_{\mathrm{s}} \times a_{\mathrm{Fe}}^{i} \times K_{\mathrm{O}}}\left(C_{\mathrm{FeO}}^{\mathrm{o}}-\frac{1}{V_{\mathrm{S}}} \int_{n_{\mathrm{CO},}, t=0}^{n_{\mathrm{CO},} t=t} \mathrm{~d} n_{\mathrm{CO}}-\frac{1}{A} \frac{1}{k_{\mathrm{FeO}}} \frac{\mathrm{d} n_{\mathrm{CO}}}{\mathrm{d} t}\right)\right]^{2}
$$

\section{CALCULATION OF VOID FRACTION}

Assuming a constant cross-sectional area for the crucible, the volume of the slag may be represented by its depth. The initial slag height $h_{0}$, the dense slag depth $h_{\text {dense }}$, and the depth of foaming slag $h_{\text {foam }}$ at any given time can be measured via the recorded X-ray video.

Table AI. Reactions and Their Equilibrium Constants Used in This Study

\begin{tabular}{ll}
\hline Reactions & \multicolumn{1}{c}{ Reaction Constant } \\
\hline$(\mathrm{FeO})=[\mathrm{Fe}]+[\mathrm{O}](1)$ & $\log K_{1}=\frac{-6372}{T}+2.73$ \\
{$[\mathrm{C}]+[\mathrm{O}]=\mathrm{CO}(2)$} & $\log K_{2}=\frac{1160}{T}+2.003$ \\
$\frac{1}{2}\left(\mathrm{O}_{2}\right)_{\text {gas }}=[\mathrm{O}](3)$ & $\log K_{3}=\frac{6120}{T}+0.18$ \\
$\mathrm{MnO}=[\mathrm{Mn}]+[\mathrm{O}](4)$ & $\log K_{4}=\frac{-15046.6}{T}+6.70$ \\
$\frac{1}{2}\left(P_{2}\right)_{\text {gas }}=[P](5)$ & $\log K_{\mathrm{P}}=\frac{8240}{T}-0.28$ \\
\hline
\end{tabular}

Then the liquid fraction of slag in the foam was calculated based on the Eq. [A7].

$$
F_{\text {liquid }}=\frac{h_{\mathrm{o}}-h_{\text {dense }}}{h_{\text {foam }}} .
$$

Then the void fraction $=1-F_{\text {liquid }}$.

For droplets with 0.014 and $0.021 \mathrm{wt}$ pctS, which go through phosphorus reversion while sitting between the dense slag and foaming slag as shown in Figure 3, the liquid fraction $F_{\text {liquid }}^{*}$ of the slag in contact with the droplet was represented by a weighted average of foamy and dense slag in proportion to their contact with the droplet, i.e.,

$$
F_{\text {liquid }}^{*}=\frac{V_{\text {droplet in the foam }}}{V_{\text {droplet }}} F_{\text {liquid } 1}+\frac{V_{\text {droplet in dense slag }}}{V_{\text {droplet }}} F_{\text {liquid } 2} \text {, }
$$

where $V_{\text {droplet }}, V_{\text {dropletinthefoam}}$, and $V_{\text {dropletindenseslag }}$ are total droplet volume, the partial volume of droplet in foaming slag and dense slag, respectively. $F_{\text {liquid } 1}$ is the slag liquid fraction obtained from Eq. [A7], while $F_{\text {liquid2 }}$ represents the liquid fraction of dense slag and is one.

The related reactions and their reaction equilibrium constants are listed in Table AI: $:^{[28]}$

In this study, the empirical equation developed by Basu et al. ${ }^{[29]}$ was also used to estimate $\gamma_{\mathrm{FeO}}$.

$$
\log \gamma_{\mathrm{FeO}}=-0.7335 \times \log X_{\mathrm{FeO}}-0.2899
$$

Slag and metal compositions taken from the work of Shibata et al. ${ }^{[4]}$ and from Wei et al. ${ }^{[2]}$ are given in Tables AII and AIII. These data are employed to calculate $k_{\mathrm{FeO}}$ and $P_{O_{2}}^{i}$ below.

\section{DYNAMIC INTERFACIAL OXYGEN POTENTIAL}

The equations employed in calculating $P_{\mathrm{O}_{2}}^{i}$ for the four cases taken from the work of Shibata et al. ${ }^{[4]}$ and Wei et al. ${ }^{[2]}$ listed in Table AII and AIII were as follows:

A-1 slag:

$$
\begin{aligned}
P_{\mathrm{O}_{2}}^{i} & =\left[\frac { \gamma _ { \mathrm { FeO } } K _ { 1 } } { C _ { \mathrm { s } } \times a _ { \mathrm { E } } ^ { i } \times K _ { 3 } } \left(C_{\mathrm{FeO}}^{\mathrm{o}}-\frac{1}{V_{\mathrm{S}}}\right.\right. \\
& \times\left(\int_{n_{\mathrm{C}}, t=\text { initial }}^{n_{\mathrm{C},}, t=t} \mathrm{~d} n_{\mathrm{C}}+2 \int_{n_{\mathrm{Si}}, t=\text { initial }}^{n_{\mathrm{Si}}, t=t} \mathrm{~d} n_{\mathrm{Si}}\right) \\
& \left.\left.-\frac{1}{A} \frac{1}{k_{\mathrm{FeO}}}\left(\frac{\mathrm{d} n_{\mathrm{C}}}{\mathrm{d} t}+2 \frac{\mathrm{d} n_{\mathrm{Si}}}{\mathrm{d} t}\right)\right)\right]^{2} .
\end{aligned}
$$

Table AII. Slag Compositions (Weight Percent)

\begin{tabular}{lllllll}
\hline Slag & $\mathrm{MnO}$ & $\mathrm{FeO}$ & $\mathrm{CaO}$ & $\mathrm{SiO}_{2}$ & $\mathrm{CaF}_{2}$ & $\mathrm{Li}_{2} \mathrm{O}$ \\
\hline Shibata et al. (A-1) & - & 29.7 & 29.4 & 32.1 & 8.8 & \\
Shibata et al. (B-12) & 22.4 & 4.5 & 30.3 & 33.3 & 9.5 & \\
Shibata et al. (C-1) & 39.6 & 5.4 & 22.0 & 23.8 & 9.2 & \\
Shibata et al. $(\mathrm{K}-5)$ & 36.7 & - & 27.6 & 27.0 & 8.8 & 17.4 \\
Wei et al. & $15\left(\mathrm{Fe}_{t} \mathrm{O}\right)$ & & 32.6 & 35 & & \\
\hline
\end{tabular}


Table AIII. Experimental Conditions and Initial Metal Compositions (Weight Percent)

\begin{tabular}{|c|c|c|c|c|c|c|}
\hline Number & Temperature $\left[\mathrm{K}\left({ }^{\circ} \mathrm{C}\right)\right]$ & $\mathrm{C}$ & $\mathrm{P}$ & $\mathrm{Si}$ & $\mathrm{Mn}$ & $\mathrm{S}$ \\
\hline Shibata et al. (A-1) & $1773(1500)$ & 3.72 & 0.089 & 0.187 & - & 一 \\
\hline Shibata et al. (B-12) & $1773(1500)$ & 3.81 & 0.092 & 0.194 & 0.015 & 一 \\
\hline Shibata et al. (C-1) & $1723(1450)$ & 3.79 & 0.102 & 0.215 & 0.010 & 一 \\
\hline Shibata et al. (K-5) & $1723(1450)$ & 3.80 & 0.096 & 0.167 & 0.020 & 0.098 \\
\hline Wei et al. $\left(P_{\mathrm{O}_{2}}=0 \mathrm{~atm}\right)$ & $1573(1300)$ & 4.44 & 0.1 & & & \\
\hline Wei et al. $\left(P_{\mathrm{O}_{2}}=0.1 \mathrm{~atm}\right)$ & $1573(1300)$ & 4.18 & 0.044 & & & \\
\hline
\end{tabular}

\section{K-5 slag:}

$$
\begin{aligned}
P_{\mathrm{O}_{2}}^{i} & =\left[\frac { \gamma _ { \mathrm { MnO } } K _ { 4 } } { C _ { \mathrm { s } } * a _ { \mathrm { Mn } } ^ { i } * K _ { 3 } } \left(C_{\mathrm{MnO}}^{\mathrm{o}}-\frac{1}{V_{\mathrm{s}}}\right.\right. \\
& \times\left(\int_{n_{\mathrm{C}, t=\text { initial }}}^{n_{\mathrm{C}, t=t}} \mathrm{~d} n_{\mathrm{C}}+2 \int_{n_{\mathrm{Si}}, t=\text { initial }}^{n_{\mathrm{Si}}, t=t} \mathrm{~d} n_{\mathrm{Si}}\right) \\
& \left.\left.-\frac{1}{A} \frac{1}{k_{\mathrm{MnO}}}\left(\frac{\mathrm{d} n_{\mathrm{C}}}{\mathrm{d} t}+2 \frac{\mathrm{d} n_{\mathrm{Si}}}{\mathrm{d} t}\right)\right)\right]^{2} .
\end{aligned}
$$

Eq. [A9] was developed by balancing the flux of FeO to the interface with the oxidation of carbon and silicon in the metal. A10 was developed in the same way replacing $\mathrm{FeO}$ flux with that of $\mathrm{MnO}$. Eq. [A11] applied the same logic but assumed oxygen supply by simultaneous flux of $\mathrm{FeO}$ and $\mathrm{MnO}$ and that $\mathrm{Mn} / \mathrm{MnO}$ and $\mathrm{Fe} /$ $\mathrm{FeO}$ at the interface were in equilibrium with the same oxygen potential. Similarly, Eq. [A12] was developed by balancing the flux of $\mathrm{FeO}$ to the interface with the oxidation of carbon in the metal. Wei et al. defined the iron oxide in their slag as $\mathrm{Fe}_{t} \mathrm{O}$ in recognition that some of the iron was present as $\mathrm{Fe}^{3+}$; however, for simplicity of calculation it has been assumed that the iron oxide was in the form of $\mathrm{FeO}$.

B-12 and C-1 slag:

$$
\begin{aligned}
P_{\mathrm{O}_{2}}^{i} & =\left[\frac{1}{\left(\frac{C_{\mathrm{s}} \times a_{\mathrm{Fe}}^{i} \times k_{\mathrm{FeO}}}{\gamma_{\mathrm{FeO}} \times K_{1}}+\frac{C_{\mathrm{s}} \times a_{\mathrm{Mn}}^{i} \times k_{\mathrm{MnO}}}{\gamma_{\mathrm{MnO}} \times K_{4}}\right) \times K_{3}}\right. \\
& \times\left[\left(k_{\mathrm{FeO}}+\frac{k_{\mathrm{MnO}} \times \gamma_{\mathrm{FeO}} \times K_{1 \times a_{\mathrm{Mn}}^{i} \times K_{4}}}{a_{\mathrm{Fe}}^{i} \times \gamma_{\mathrm{MnO}}}\right)\right. \\
& \times\left(C_{\mathrm{FeO}}^{\mathrm{o}}-\frac{1}{V_{\mathrm{s}}}\left(\int_{n_{\mathrm{C}}, t=\text { initial }}^{n_{\mathrm{C}}, t=t} \mathrm{~d} n_{\mathrm{C}}+2 \int_{n_{\mathrm{Si}}, t=\text { initial }}^{n_{\mathrm{S}}, t=t} \mathrm{~d} n_{\mathrm{Si}}\right)\right) \\
& \left.\left.-\frac{1}{A}\left(\frac{\mathrm{d} n_{\mathrm{C}}}{\mathrm{d} t}+2 \frac{\mathrm{d} n_{\mathrm{Si}}}{\mathrm{d} t}\right)\right]\right]^{2}
\end{aligned}
$$

$\mathrm{Fe}_{t} \mathrm{O}$ slag:

$$
P_{\mathrm{O}_{2}}^{i}=\left[\frac{\gamma_{\mathrm{FeO}} K_{1}}{C_{\mathrm{S}} \times a_{\mathrm{Fe}}^{i} \times K_{3}}\left(C_{\mathrm{FeO}}^{\mathrm{o}}-\frac{1}{V_{\mathrm{s}}} \int_{n_{\mathrm{C}}, t=\text { initial }}^{n_{\mathrm{C}}, t=t} \mathrm{~d} n_{\mathrm{C}}-\frac{1}{A} \frac{1}{k_{\mathrm{FeO}}} \frac{\mathrm{d} n_{\mathrm{C}}}{\mathrm{d} t}\right)\right]^{2},
$$

where $\gamma$ is the Raoult's activity coefficient of oxides in the slag at the interface and calculated via Eq. [A11], $\alpha^{i}$ represents the Henrian activity in liquid metal at the interface and obtained based on interaction coefficients for different solutes. ${ }^{[17]} K$ is the equilibrium constant for reactions listed in Table AIV, $C_{\mathrm{s}}$ and $C^{\mathrm{o}}$ are molar density of slag and initial concentration of oxides, respectively. $V_{\mathrm{s}}$ represents the volume of slag, $\frac{d_{n}}{\mathrm{~d}_{t}}$ is the reaction rate (mole/s) for $\mathrm{Si}$ and $\mathrm{C}$ which is determined empirically using experimental data.

\section{MASS TRANSFER COEFFICIENT $\boldsymbol{K}_{\text {FEO }}$ CONVER- SION}

If the reduction of iron oxide in FeO-rich slag follows first-order reaction kinetics with respect to $\mathrm{FeO}$ in the bulk slag phase and is controlled by the mass transfer of $\mathrm{FeO}$ in the slag, the rate expression may be given as follows:

$$
r_{\mathrm{FeO}}=k(\text { pct FeO })_{\text {bulk slag }}
$$

where $r_{\mathrm{FeO}}$ is reaction rate with the unit of (pct $\mathrm{FeO}) \times \mathrm{s}^{-1}$ and also equal to the reaction rate in terms of $\mathrm{CO}$, i.e., $r_{\mathrm{CO}} ; k$ is the rate constant and has a unit of $\mathrm{s}^{-1}$ or $\min ^{-1}$. It is well known that the firstorder reaction rate can also be written as:

$$
\begin{aligned}
r_{\mathrm{FeO}} & =k_{\mathrm{FeO}} \frac{A}{V}(\text { pct FeO })_{\text {bulk slag }} \\
= & k_{\mathrm{FeO}} \frac{A}{A h_{\mathrm{O}}}(\text { pct FeO })_{\text {bulk slag }}=\frac{k_{\mathrm{FeO}}}{h_{\mathrm{o}}}(\text { pct FeO })_{\text {bulk slag }},
\end{aligned}
$$

where $k_{\mathrm{FeO}}$ is mass transfer coefficient of $\mathrm{FeO}, V$ represents slag volume in this case, $A$ is the area of slag-metal interface and normally treated as cross-sectional area of crucible, $h_{\mathrm{o}}$ represents the slag height.

Then we are able to convert the rate constant (with unit of $\mathrm{s}^{-1}$ ) in Eq. [A13] to $k_{\mathrm{FeO}}$ via the following expression.

$$
k=\frac{k_{\mathrm{FeO}}}{h_{\mathrm{O}}} .
$$

Some authors expressed the reaction rate as in Eq. [A16] with the unit of $\mathrm{mol} \times \mathrm{cm}^{-2} \times \mathrm{s}^{-1}$, 
Table AIV. Converted $k_{\mathrm{FeO}}$ from Rate Constants Determined by Different Researchers

\begin{tabular}{|c|c|c|c|c|c|c|c|c|c|}
\hline Investigator & $T\left[\left(\mathrm{~K}\left({ }^{\circ} \mathrm{C}\right)\right]\right.$ & $B$ & $\begin{array}{c}\mathrm{Fe}_{t} \mathrm{O} \\
(\mathrm{Wt} \mathrm{Pct})\end{array}$ & $k^{\prime} \times$ & $\begin{array}{l}10^{7}\left(\mathrm{~mol} \times \mathrm{cm}^{-2} \times \mathrm{s}^{-1}\right. \\
\left.\quad(\mathrm{Pct} \mathrm{FeO})^{-1}\right)\end{array}$ & $k \times 10^{3}\left(\mathrm{~s}^{-1}\right)$ & \multicolumn{3}{|c|}{$k_{\mathrm{FeO}} \times 10^{3}(\mathrm{~cm} / \mathrm{s})$} \\
\hline $\mathrm{Li}$ and Barati. & $1873(1600)$ & 1.8 & 10 & \multicolumn{2}{|r|}{1.1} & & \multicolumn{3}{|c|}{0.30} \\
\hline $\mathrm{Li}$ and Barati & $1873(1600)$ & 1.8 & 18 & \multicolumn{2}{|r|}{4.1} & & \multicolumn{3}{|c|}{1.12} \\
\hline Li and Barati & $1873(1600)$ & 1.8 & 25 & \multicolumn{2}{|r|}{7.6} & & \multicolumn{3}{|c|}{2.07} \\
\hline Paramguru et al. & $1673(1400)$ & 1 & 20 & & & 1.58 & \multicolumn{3}{|c|}{2.79} \\
\hline Paramguru et al. & $1673(1400)$ & 1 & 20 & & & 1.62 & \multicolumn{3}{|c|}{2.86} \\
\hline Paramguru et al. & $1673(1400)$ & 1 & 30 & & & 2.45 & \multicolumn{3}{|c|}{4.14} \\
\hline Paramguru et al. & $1673(1400)$ & 1 & 40 & & & 3.16 & \multicolumn{3}{|c|}{5.12} \\
\hline Bhoil et al. & $1873(1600)$ & 1 & 20 & & & 3.33 & \multicolumn{3}{|c|}{12.0} \\
\hline Bhoil et al. & $1873(1600)$ & 1 & 30 & & & 3.53 & \multicolumn{3}{|c|}{12.7} \\
\hline Bhoil et al. & $1873(1600)$ & 1 & 40 & & & 3.80 & \multicolumn{3}{|c|}{13.7} \\
\hline Galgali et al. & $1773(1500)$ & 1.2 & 3.0 & & & 0.82 & \multicolumn{3}{|c|}{2.45} \\
\hline Galgali et al. & $1773(1500)$ & 1.2 & 4.6 & & & 1.42 & \multicolumn{3}{|c|}{4.26} \\
\hline Galgali et al. & $1773(1500)$ & 1.2 & 10.7 & & & 2.0 & \multicolumn{3}{|c|}{6.0} \\
\hline Galgali et al. & $1773(1500)$ & 1.2 & 16.4 & & & 2.45 & \multicolumn{3}{|c|}{7.35} \\
\hline Galgali et al. & $1773(1500)^{*}$ & 1.2 & 5 & & & & \multicolumn{3}{|c|}{3.78} \\
\hline Galgali et al. & $1773(1500)^{*}$ & 1.2 & 10 & & & & \multicolumn{3}{|c|}{3.80} \\
\hline Galgali et al. & $1773(1500)^{*}$ & 1.2 & 15 & & & & \multicolumn{3}{|c|}{2.90} \\
\hline Galgali et al. & $1773(1500)^{*}$ & 1.2 & 20 & & & & \multicolumn{3}{|c|}{2.36} \\
\hline Murthy et al. & $1723(1450)^{* *}$ & 1.1 & 8.4 & & & 4.31 & \multicolumn{3}{|c|}{$1.25 * *$} \\
\hline \multicolumn{10}{|c|}{$k \times 10^{5}\left(\mathrm{~mol} \times \mathrm{cm}^{-2} \times \mathrm{s}^{-1}\right)$} \\
\hline Murthy et al. & $1823(1550)^{*}$ & & 1.1 & 5.5 & 1.4 & & & & 6.62 \\
\hline Murthy et al. & $1823(1550)^{*}$ & & 1.1 & 8.4 & 1.88 & & & & 5.74 \\
\hline Murthy et al. & $1823(1550)^{*}$ & & 1.1 & 13.2 & 2.05 & & & & 3.89 \\
\hline Murthy et al. & $1823(1550)^{*}$ & & 1.1 & 18 & 2.6 & & & & 3.55 \\
\hline
\end{tabular}

*Those values were not brought into the discussion of Fig. 5.

**This value of mass transfer coefficient is the mean value for slag with constant $\mathrm{FeO}$ content but different slag weights.

$$
\begin{aligned}
r_{\mathrm{FeO}} & =J_{\mathrm{FeO}}=k_{\mathrm{FeO}} C_{\mathrm{FeO} \text { bulk slag }} \\
& =k_{\mathrm{FeO}} \frac{\rho_{\mathrm{s}}}{100 M_{\mathrm{FeO}}}(\text { pet FeO })_{\text {bulk slag }},
\end{aligned}
$$

where $\rho_{\mathrm{s}}$ is the density of slag $\left(g \times \mathrm{cm}^{-3}\right), M_{\mathrm{FeO}}$ represents the molecular weight of $\mathrm{FeO}$.

Then Eq. [A13] can be rewritten as:

$$
r_{\mathrm{FeO}}=k^{\prime}(\text { pet } \mathrm{FeO})_{\text {bulk slag }} \text {. }
$$

Similarly, $r_{\mathrm{FeO}}$ is reaction rate but with the unit ofmol $\times \mathrm{cm}^{-2} \times \mathrm{s}^{-1}$ and $k^{\prime}=k_{\mathrm{FeO}} \frac{\rho_{\mathrm{s}}}{100 M_{\mathrm{FeO}}}$ is the rate constant with the unit of $\mathrm{mol} \times \mathrm{cm}^{-2} \times \mathrm{s}^{-1}$ $(\text { pct } \mathrm{FeO})^{-1}$. Therefore, $k^{\prime}$ can be converted to $k_{\mathrm{FeO}}$ based on Eq. [A16].

\section{REFERENCES}

1. S. Ohguchi, D.G.C. Robertson, B. Deo, P. Grieveson, and J.H.E. Jeffes: Ironmak. Steelmak., 1984, vol. 11, pp. 202-13.

2. P. Wei, M. Ohya, M. Hirasawa, M. Sano, and K. Mori: ISIJ. Int., 1993, vol. 33 (8), pp. 847-54.

3. B.J. Monaghan, R.J. Pomfret, and K.S. Coley: Metall. Trans. B, 1998, vol. 29B, pp. 111-18.

4. E. Shibata, H. Sun, and K. Mori: Metall. Trans. B, 1999, vol. 30B, pp. $279-86$.

5. K. Gu, N. Dogan, and K. Coley: Metall. Trans. B.

6. E. Chen and K. Coley: Ironmak. Steelmak., 2010, vol. 37 (7), pp. $541-45$.

7. H. Sun: ISIJ Int., 1993, vol. 33 (11), pp. 1560-69.

8. T. Mori: Trans. Jpn. Inst. Met., 1984, vol. 25 (11), pp. 761-71.
9. C.L. Molloseau and R.J. Fruehan: Metall. Trans. B, 2002, vol. 33B, pp. 335-44.

10. B. Sarma: PhD Thesis, Carnegie Mellon University, Pittsburgh, PA, 1992, pp. 30-31 and 149 .

11. D.J. Min and R.J. Fruehan: Metall. Trans. B, 1992, vol. 23B, pp. 29-37.

12. P. Wei, M. Sano, M. Hirasawa, and K. Mori: ISIJ Int., 1993, vol. 33, pp. 479-87.

13. H. Gou, G.A. Irons, and W. Lu: Metall. Trans. B, 1996, vol. 27B, pp. $79-88$.

14. T. Zhu, M.P. King, K.S. Coley, and G.A. Irons: Metall. Trans. B, 2012, vol. 43B, pp. 31-36.

15. S. Jung and R.J. Fruehan: ISIJ Int., 2000, vol. 40 (4), pp. 348-55.

16. J. Li and M. Barati: Metall. Trans. B, 2009, vol. 40B, pp. 17-24.

17. R.K. Galgali, P. Datta, A.K. Ray, K.K. Prasad, and H.S. Ray: Ironmak. Steelmak., 2001, vol. 28 (4), pp. 321-28.

18. G.G. Krishna Murthy, Y. Sawada, and J.F. Elliot: Ironmak. Steelmak., 1993, vol. 20 (3), pp. 179-90.

19. G.G. Krishna Murthy, A. Hasham, and U.B. Pal: ISIJ Int., 1994, vol. 34 (5), pp. 408-13.

20. R.K. Paramguru, H.S. Ray, and P. Basu: Ironmak. Steelmak., 1996, vol. 23 (4), pp. 328-34

21. R.K. Paramguru, H.S. Ray, and P. Basu: ISIJ Int., 1997, vol. 37 (8), pp. 756-61.

22. R.K. Paramguru, R.K. Galgali, and H.S. Ray: Metall. Trans. B, 1997, vol. 28B, pp. 805-10.

23. B. Bhoi, A.K. Jouhari, H.S. Ray, and V.N. Misra: Ironmak. Steelmak., 2006, vol. 33 (3), pp. 245-52.

24. D.E. Woolley and U.B. Pal: ISIJ Int., 1999, vol. 39 (2), pp. 103-12.

25. M. Barati and K. Coley: Metall. Trans. B, 2006, vol. 37B, pp. 51-60.

26. M. Barati and K. Coley: Metall. Trans. B, 2006, vol. 37B, pp. 41-49.

27. C. Cicutti, M. Valdez, T. Perez, R. Donayo, and J. Petroni: Lat. Am. Appl. Res., 2002, vol. 32, p. 237.

28. M. Hino and K. Ito: Thermodynamic Data for Steelmaking, Tohoku University Press, Sendai, 2009, pp. 259-64.

29. S. Basu, A.K. Lahiri, and S. Seetharaman: Metall. Trans. B, 2008, vol. 39 B, pp. $447-56$. 